\title{
Quarter Car Active Suspension System Control using Fuzzy Controller tuned by PSO
}

\author{
Wissam H. Al-Mutar \\ Electrical Eng. \\ College of Engineering \\ Basrah University \\ Basrah. Iraq
}

\author{
Turki Y. Abdalla \\ Computer Eng. \\ College of Engineering \\ Basrah University \\ Basrah. Iraq
}

\begin{abstract}
The objective of this paper is to design an efficient control scheme for car suspension system. The purpose of suspension system in automobiles is to improve more comfortable riding and good handling with road profile. A nonlinear hydraulic actuator is added to passive suspension system in parallel with damper. The Particles Swarm Optimization (PSO) is used to design a Fuzzy controller for active suspension system. The designed controller is applied for quarter car suspension system and result is compared with passive suspension system model. Simulation results show good performance for the designed controller.
\end{abstract}

\section{General Terms}

Fuzzy control, PSO algorithm, passive suspension system, simi-active suspension system, active suspension system.

\section{Keywords}

Active suspension system, FLC, PSO.

\section{INTRODUCTION}

At the begging it should be know what the suspension system in car is, by classifying suspension systems into three types (passive, simi-active and active). Figures (1-3) below show the three types of Quarter car suspension system and hydraulic actuator position in the system. [1]

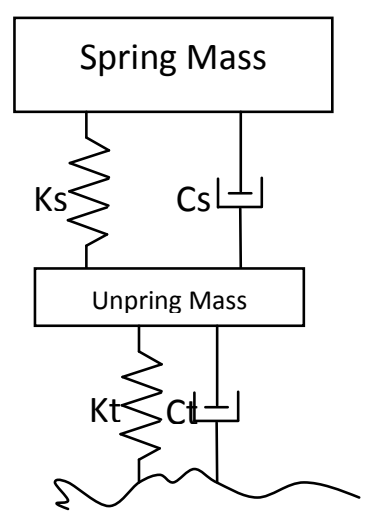

Fig 1: Passive Quarter Car Model

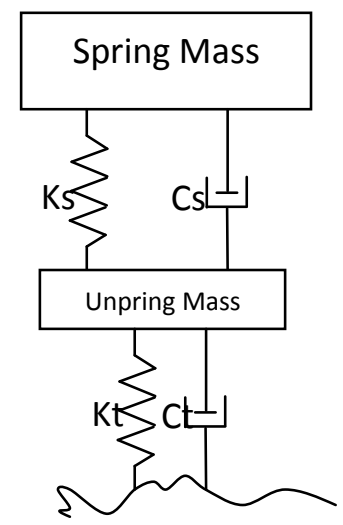

Fig 2: Simi-active Quarter Car Model

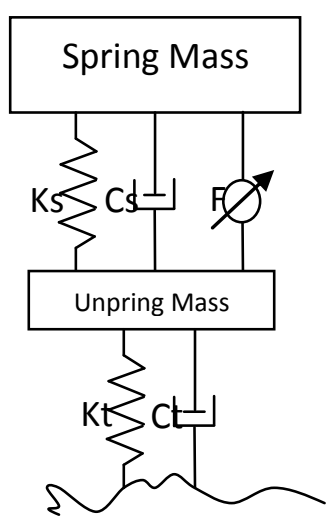

Fig 3: Active Quarter Car Model

These dumpers are used to decrease the effect of road profile and vibration effects into driver and passenger's cabin. In active suspension system there are used three parts under spring mass (body of car), spring, dumper and hydraulic actuator connected in parallel. In this paper an additional parts is added to passive suspension system in parallel with springs and dumpers called a hydraulic actuator to get an active suspension system. This hydraulic actuator is used a nonlinear part and it is controlled by spool valve. The mechanism of this actuator is to decrease the effect road profile and vibration from passive suspension system to get more comfortable riding. By using fuzzy logic controller (FLC) trained by Particle Swarm Optimization (PSO) to find optimal values of scaling gains in each inputs and output, and optimal position for centers of membership function. MATLAB/Simulink will be use to simulate a quarter car 
model and auto tuning FLC parameters by PSO algorithm. Mathematical equations can be represented as the quarter car model and then simulated in MATLAB. Also, by comparison with passive suspension system's response the best response can be reached by tuning for FLC using PSO. Kurniawan Eka Permana and Siti Zaiton Mohd Hashim [2] found out FLC membership function in manual properly is time losing, results may be have errors and difficult, especially it depends on an expert. FLC tuned by PSO algorithm give us a successfully prove to find optimal position of membership function centers automatically. Yu Yang, Wen-Ge Wang, DeJie Yu and Ge Ding [3] got effective results more than PID controller that used in active suspension system. A. A. AlDair and W. J. Wang [4] deduce the active suspension system output (vibration in passenger's cabin) in nero-fuzzy case is better than output of Fractional Order PID (FOPID) in stability, performance and good handling. M. V. C. Rao and V. Prahad [10] got a results better ride comfort. Also, fuzzy controller has wide range of parameters but they attend to demonstrate results in active suspension system. M. M. M. Salem, and Ayman A. Aly [12] used PID and fuzzy controllers and they proved that the second one is better than the first one, and may be used in future as manufacture basis to product vehicle with modern active suspension system. Simulation and results of the active suspension system with fuzzy logic controller also show the improved stability, good handling performance of the quarter car model. Zhaolong Cao [13] arrived to the analysis of simulation that give good performance of active suspension compared with passive suspension system. The comfortable riding and handling has been improved. The universe of the variables for fuzzy control depend on fuzzy inference can improve the control environment of active suspension system.

\section{MODELING OF ACTIVE SUSPENSION SYSTEM OF QUARTER CAR MODEL}

The quarter car model shown below in Figure (4), is used for active suspension system.

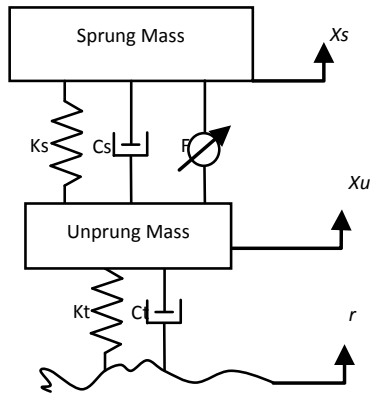

Fig 4: Quarter Car Model active suspension system

with:

Ms: car chassis mass.

$M u$ : wheel mass.

$K s$ : Spring Stiffness.

$K t$ : Tire Stiffness corresponded to spring.

Cs: Dumper force.

$C t$ : Tire force corresponded to dumber

$F$ : Actuator force.

$X s$ : Body displacement.

$X u$ : Wheel displacement.

$r$ : Road profile.
Now by Newton's laws quarter car model active suspension system can be written as shown in the following equations:

Spring mass part

$\mathrm{Ms} \ddot{\mathrm{X}} \mathrm{s}+\mathrm{Ks}(\mathrm{X} s-\mathrm{Xu})+\mathrm{Cs}(\dot{\mathrm{X}} \mathrm{s}-\dot{\mathrm{Xu}})-\mathrm{F}=0$

Unspring mass part

$\mathrm{MuXu}+\mathrm{Kt}(\mathrm{Xu}-\mathrm{r})+\mathrm{Ct}(\dot{\mathrm{Xu}}-\dot{\mathrm{r}})-\mathrm{Ks}(\mathrm{Xs}-\mathrm{Xu})-\mathrm{Cs}(\dot{\mathrm{X}} \mathrm{s}-$

$\mathrm{Xu})+\mathrm{F}=0$

A three land four-way spool valve is based on the hydraulic actuator in this design [4], [8], [9].

$\dot{\mathrm{Pl}}=-\beta \mathrm{Pl}-\sigma \mathrm{Ap}(\dot{\mathrm{Xs}}-\dot{\mathrm{Xu}})+\gamma \mathrm{Xv} \sqrt{(\mathrm{Ps}-\mathrm{Pl} \operatorname{Sgn}(\mathrm{Xv})}$

Where:

Ps: Supply pressure.

$X v$ : Spool displacement of servo valve.

$\dot{\mathrm{X} v}=\frac{1}{\tau}(\mathrm{Um}-\mathrm{Xv})$

$X v$ : Valve displacement.

Um: Control signal to Spool.

$\mathrm{F}=\mathrm{Pl} \mathrm{Ap}$

$A p$ : Cross section area of actuator piston [4].

Now, to get state space forms define the following:

Let:

$X_{1}=X s-X u$

$X_{2}=\dot{X} s$

$X_{3}=X u-r$

$X_{4}=\dot{X u}$

$X_{5}=P l$

$X_{6}=X v$

By subscribe the above assumptions, state space equations became.

$\dot{\mathrm{X}}_{1}=\mathrm{X}_{2}-\mathrm{X}_{4}$

$\dot{X}_{2}=-\frac{\mathrm{Ks}}{\mathrm{Ms}} \mathrm{X}_{1}-\frac{\mathrm{Cs}}{\mathrm{Ms}} \mathrm{X}_{2}+\frac{\mathrm{Cs}}{\mathrm{Ms}} \mathrm{X}_{2}+\frac{\mathrm{Ap}}{\mathrm{Ms}} \mathrm{X}_{5}$

$\dot{\mathrm{X}}_{3}=\mathrm{X}_{4}-\dot{\mathrm{r}}$

$\dot{X}_{4}=-\frac{\mathrm{Kt}}{\mathrm{Mu}} \mathrm{X}_{3}-\frac{\mathrm{Ct}}{\mathrm{Mu}} \mathrm{X}_{4}+\frac{\mathrm{Ks}}{\mathrm{Mu}} \mathrm{X}_{1}+\frac{\mathrm{Cs}}{\mathrm{Mu}} \mathrm{X}_{2}-\frac{\mathrm{Cs}}{\mathrm{Mu}} \mathrm{X}_{4}-\frac{\mathrm{Ap}}{\mathrm{Mu}} \mathrm{X}_{5}$.(9)

$\dot{X}_{5}=-\beta \mathrm{X}_{5}-\sigma \mathrm{ApX}_{2}+\sigma \mathrm{ApX}_{4}+\gamma \mathrm{X}_{6} \sqrt{\left(\mathrm{Ps}-\mathrm{X}_{5} \operatorname{Sgn}\left(\mathrm{X}_{6}\right)\right.}$

$\dot{\mathrm{X}}_{6}=\frac{1}{\tau}\left(\mathrm{Um}-\mathrm{X}_{6}\right)$

3. FUZZY LOGIC CONTROLLER (FLC)

Two inputs body speed $\dot{X}_{S}$ and body acceleration $\ddot{X}_{S}$ in fuzzy logic controller used with quarter active suspension system and one output represents actuator spool valve signal. FLC consists of three levels first one is fuzzification, second level fuzzy inference and the third level represent defuzzification. Crisp number applied to FLC should be converted to a number between $(0,1)$ with respect to its value, this operation called Fuzzification and this is done by based on fuzzy rule table depending on physical system's prosperities, this process called fuzzy inference. After taking the decision from fuzzy rule, FLC gives an output, defuzzification process will be given to the system as crisp value from FLC [11]. Figure 5 below describe quarter car active suspension system with FLC and speed of sprung mass as an error feedback. 


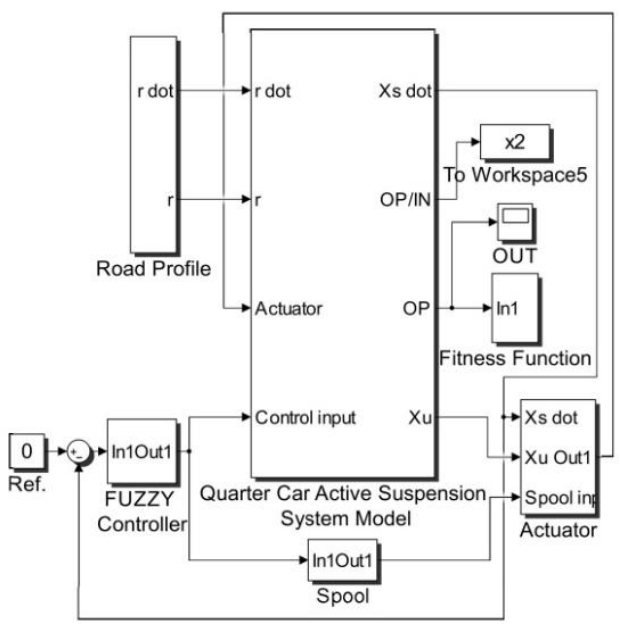

Fig 5: Quarter car active suspension system with FLC

The block fuzzy controller in fig. 5 is shown in fig. 6

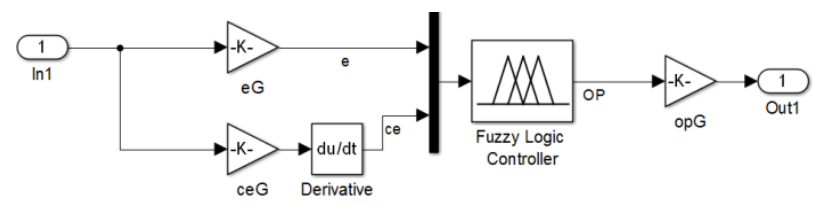

Fig 6: Contents of fuzzy controller

Figure 6 contain three gains, two at input lines (error and change of error) and third one in the output line. These gains represent scaling factors.

\section{PARTICALE SWARM OPTIMIZATION}

Particle Swarm Optimization (PSO) Put forward by Dr.Eberhart and Dr. Kennedy in 1995 [13], they took over from the bird predation behavior as a simulation, by tracking two "extreme" to upgrade their position and velocity they will start with initializing a random population where each particle in the population shows a potential solution to solve the problem. Each one of the iteration has its right position and speed for every particle.

To find the optimal solution every individual extreme value will be chosen respectively. The local positions are generated through iterations and themselves lead us to the global position. Each individual particle $i$ has the following details. A current position in problem surrounding, $x_{i d}$, a current velocity, $\mathrm{p}_{\mathrm{id}}$, and a best position in problem surrounding, $\mathrm{p}_{\mathrm{id}}$. The best position, $p_{\text {id }}$, corresponds to the position in problem surrounding where the smallest error is referred as particle $i$ as defined by function. The lowest error among the particles value is the global best position $p_{g d}[13]$. When it finds the best extreme value by the formula (12), (13) it will automatically upgrade position and speed.

$V^{i+1}=$

$w \cdot V^{i}+c 1 \cdot$ rand. $\left(\right.$ Pbest $\left.^{i}-X^{i}\right)+c 2 \cdot$ rand.$\left(\right.$ gbest $\left.^{i}-X^{i}\right)$

$X^{i+1}=X^{i}+V^{i+1}$
Steps in PSO algorithm can be listed as below:

1. Our work will start by assuming a random position to each particle in the swarm.

2. Calculating the fitness function (mean square error in this paper) for each particle.

3. Comparing each particle's fitness with its $p_{\text {best, }}$ result can be gotten from the better current value to assign it as the $p_{\text {best. }}$

4. The result of the best fitness value refers as guest and its position as $\mathrm{p}_{\mathrm{gd}}$.

5. Upgrading values of the velocities and positions of all the particles using (1) and (2).

6. Back to steps 2-5 until maximum number of iteration stops for a sufficiently right fitness value. [14].

\section{FLC OPTIMIZED BY PSO}

Optimization technique uses PSO algorithm to find optimal positions for output membership function of FLC and find optimal value for output gain to get suitable response for quarter car active suspension system. Figure 7 shows quarter car model with FLC optimized by PSO algorithm. Also, figure 6 uses two inputs gain as normalization factors to keep $e(t)$ and $c e(t)$ within the range of $(-1,1)$

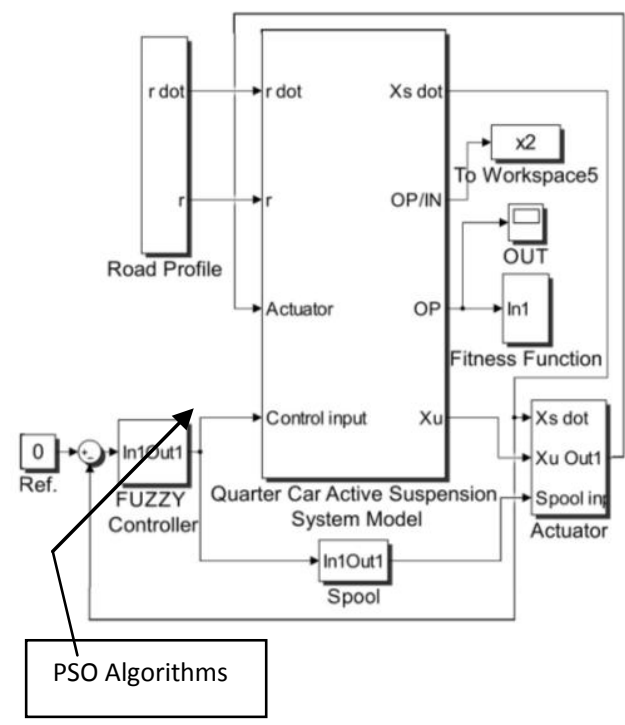

Fig 7: Quarter car active suspension system with FLC

\section{Optimized by PSO algorithms}

The following algorithm in figure 8 are applied in this paper to find optimal values for both gains and membership function MSF positions. 


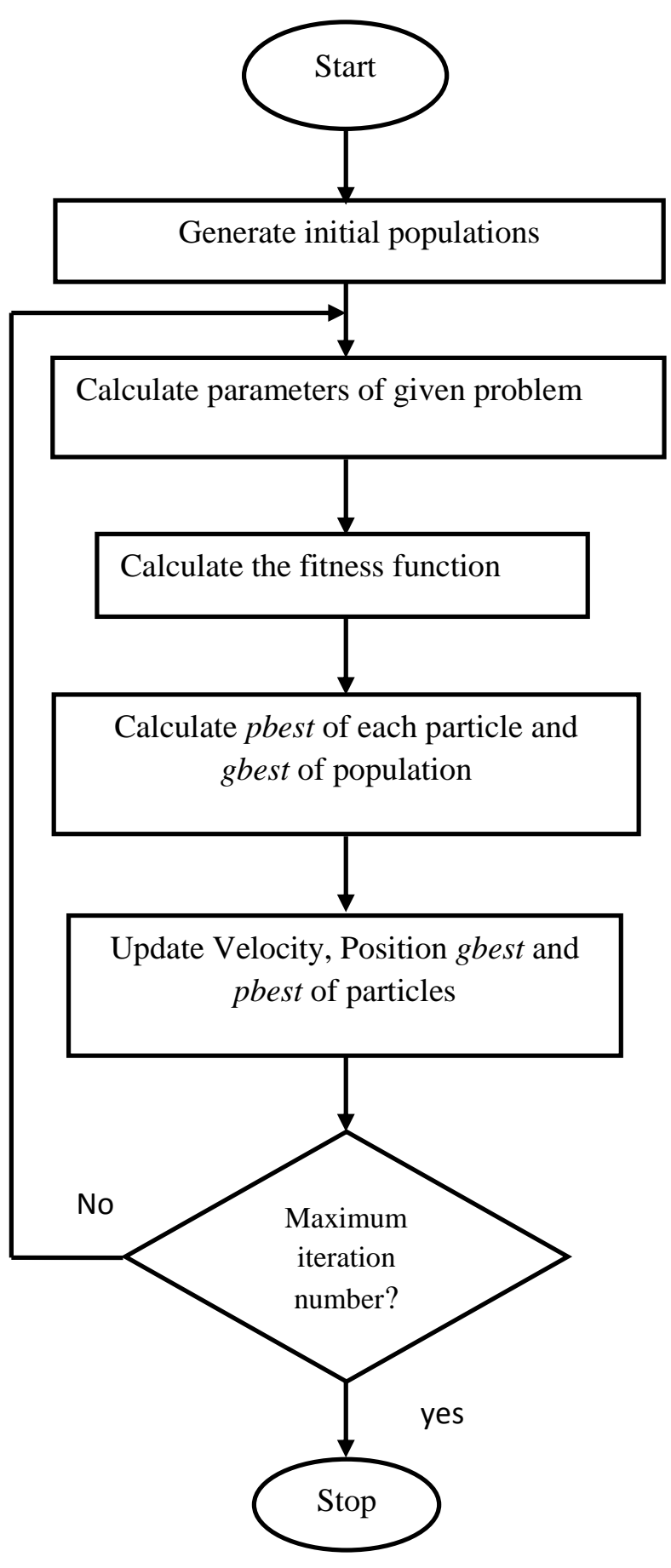

Fig 8: PSO Flow Chart for centers of MSF

Quarter car model active suspension system's parameters used in the simulation are listed in table 1 [4].

Table 1. Quarter car model active suspension system's parameters

\begin{tabular}{|c|c|c|}
\hline Parameter & Value & Unit \\
\hline$K s$ & 19960 & $\mathrm{~N} / \mathrm{m}$ \\
\hline$K t$ & 175500 & $\mathrm{~N} / \mathrm{m}$ \\
\hline$C s$ & 1290 & $\mathrm{~N} . \mathrm{sec} / \mathrm{m}$ \\
\hline$C t$ & 14.6 & $\mathrm{~N} . \mathrm{sec} / \mathrm{m}$ \\
\hline
\end{tabular}

\begin{tabular}{|c|c|c|}
\hline$M s$ & 290 & $\mathrm{Kg}$ \\
\hline$M u$ & 40 & $\mathrm{Kg}$ \\
\hline$\beta$ & 1 & - \\
\hline$\sigma$ & $4.515^{*} 10^{13}$ & - \\
\hline$\gamma$ & $1.545^{*} 10^{9}$ & - \\
\hline$\tau$ & $1 / 30$ & $\mathrm{sec}$ \\
\hline
\end{tabular}

PSO algorithm parameters are number of birds is hundred birds, number of iterations is one hundred twenty five iterations, inertia weight factor is 0.9 , social constant and cognitive constant c1, c2 respectively are ordered by when they summed together result should be equal to or less than 4 . The proposed membership functions which is used in this controller are shown in figure 9.
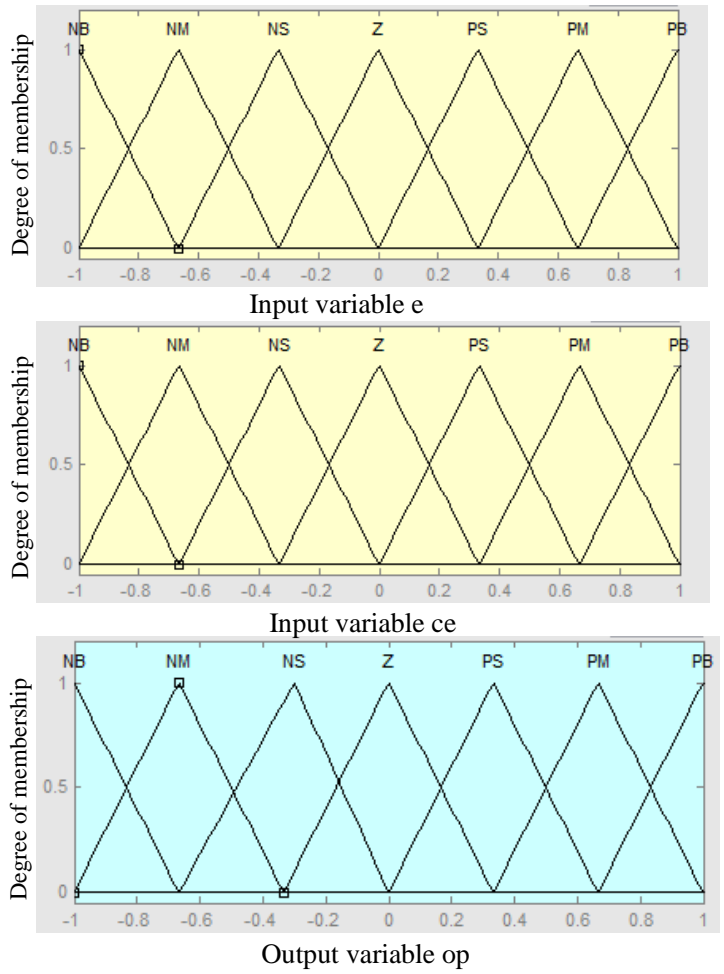

Fig 9: Propose Membership Functions of FLC

Each membership function ( $e, c e$ and $o p$ ) consists of seven fuzzy set and can be named as Negative Big (NB), Negative Medium (NM), Negative Small (NS), Zero (Z), Positive Big (PB), Positive Medium (PM) and Positive Small (PS). Fuzzy rules can be shown in table 2 .

Table 2: Rules of Fuzzy output

\begin{tabular}{|c|c|c|c|c|c|c|c|c|}
\hline \multicolumn{10}{|c|}{} & & NB & NM & NS & Z & PS & PM & PB \\
\cline { 2 - 9 } & NB & NB & NB & NB & NB & NM & NS & Z \\
\cline { 2 - 9 } & NM & NB & NB & NB & NM & NS & Z & PS \\
\cline { 2 - 9 } & NS & NB & NB & NM & NS & Z & PS & PM \\
\cline { 2 - 9 } & Z & NB & NM & NS & Z & PS & PM & PB \\
\cline { 2 - 9 } & PS & NM & NS & Z & PS & PM & PB & PB \\
\cline { 2 - 9 } & PM & NS & Z & PS & PM & PB & PB & PB \\
\cline { 2 - 9 } & PB & Z & PS & PM & PB & PB & PB & PB \\
\hline
\end{tabular}


The values of gains that were used for inputs of FLC are (2.5) and (4.2) for $e G$ and $c e G$ respectively. The scaling gain $o p G$ represents output gain yielded from PSO algorithm and equal to (25.8077), additional to optimal centers for output membership function shown in figure 10. From this figure the difference between proposed and optimal output membership functions is clear since the positions for centers are moved along $\mathrm{x}$-axis. This algorithm is specialized to find out just output membership function centers and output gain $o p G$, so with more complicated systems can change this algorithm to find out inputs and output centers also of FLC.

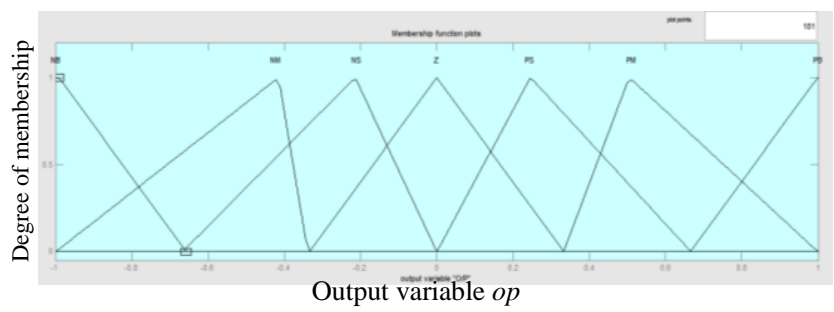

Fig 10: Propose MSF of FLC

Before showing the last results, passive system response should be described with road profile inputs as shown in the following figure 11 below, where this figure represents vertical displacement of body mass Xs (sprung mass)

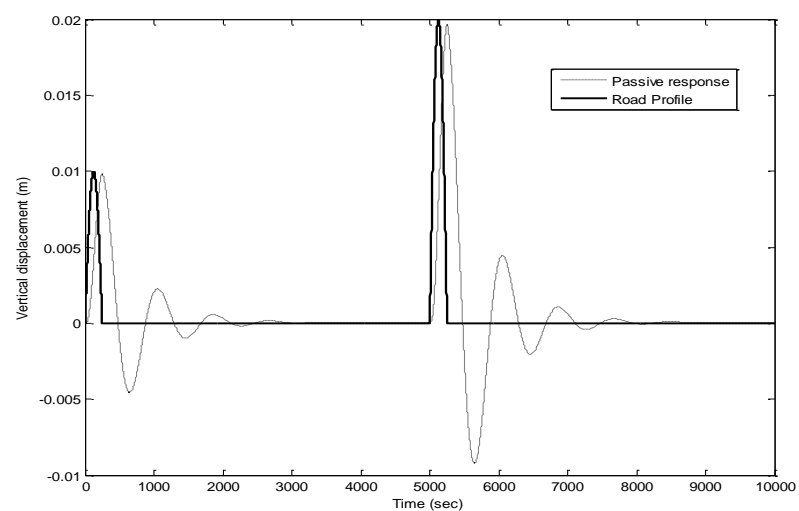

Fig 11: Vertical travel for passive quarter car model

Results of PSO algorithm (membership function's centers and output gain) are used in quarter car active suspension system. Vertical displacement of sprung mass represents the output response of quarter car active suspension system is shown in figure 12 .

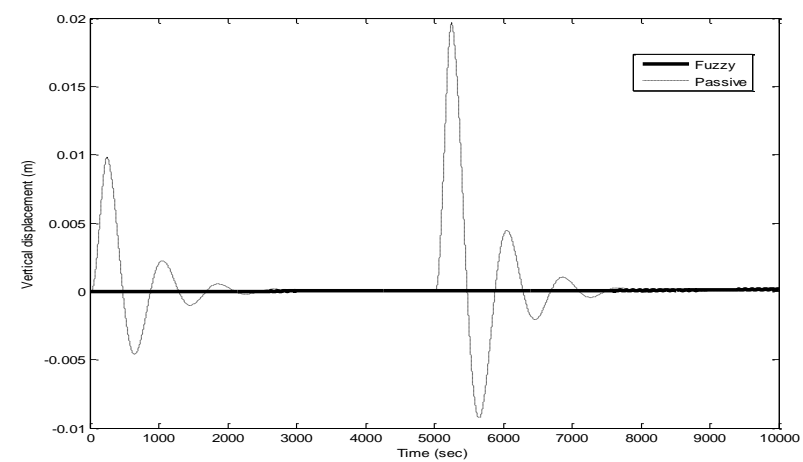

Fig 12: Vertical travel for FLC and passive quarter car model
By applying another input road profile type (sinusoidal) with $0.01 \mathrm{~m}$ amplitude, figure 13 below shows the difference between passive and FLC response

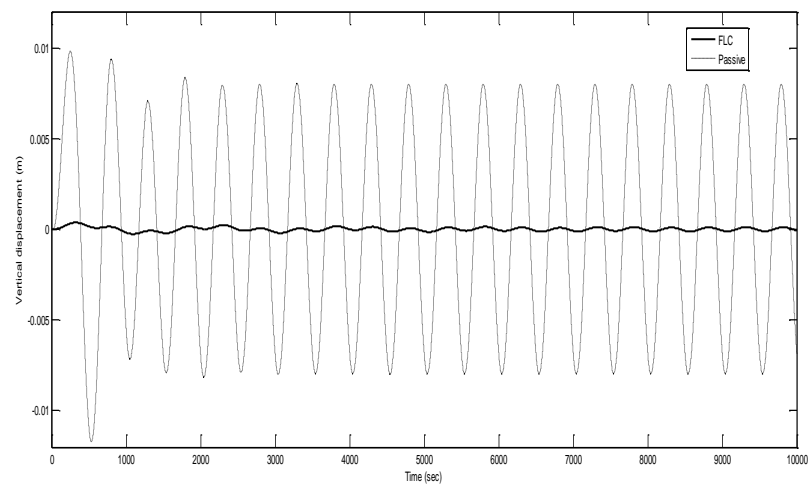

Figure 13: Vertical travel for FLC and passive quarter car model with sinusoidal road profile

Figure 14 represents Mean square error MSE with number of iterations, when PSO algorithm works MSE started with error equal to 15.867. The error is decreased during PSO work till $3.92 * 10^{-5}$ at the end of these iterations.

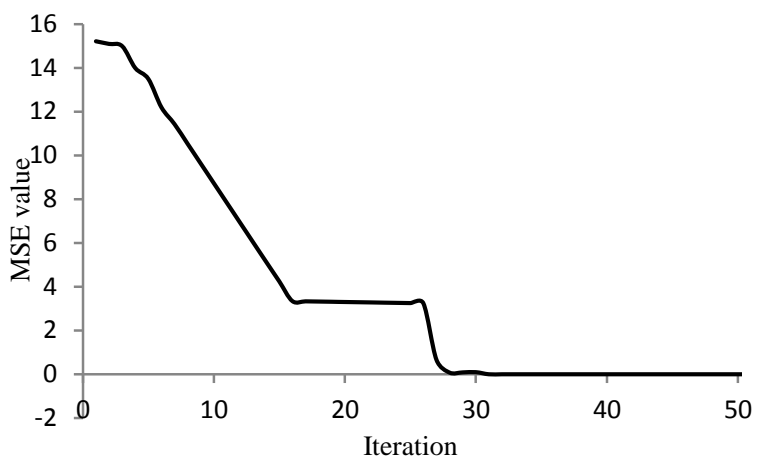

Fig 14: MSE Curve

\section{CONCLUSION}

FLC controller is designed by PSO for quarter car active suspension system model to improve more comfortable ride comparison with passive model, by increasing iterations in PSO algorithm to find optimal position for centers of MSF it has been noticed that the sprung mass displacement has been reduced around by $96.53 \%$ which shows good improvement in ride comfort and sprung mass and good handing. The theory shown in this paper should be applied for half and full nonlinear active suspension systems by improving the system's FLC to decrease vibration that comes from road profile. The idea used in this paper is seeking for optimal centers of MSF, it can developed by seeking for optimal bases and centers together of MSF or just bases of MSF, all these items need more parameters and will be more complicated in PSO algorithm's design.

\section{REFERENCES}

[1] Ian Fialho and Gary J. Balas, Member, IEEE." Road Adaptive Active Suspension Design Using Linear Parameter-Varying Gain-Scheduling," IEEE Transactions on Control Systems Technology, Vol. 10, No. 1, January 2002. 
[2] Dr. Shibly Ahmed Al-Samarraie, Dr. Muhsin N.Hamza \&YasirKhudhair AbbasWest, "Design of a Nonlinear Robust Controller for Vibration Control of a Vehicle Suspension System," Eng.\& Tech. Journal ,Vol. 29, No.11, 2011

[3] A. Aldair and W. J. Wang, "Design an Intelligent Controller for Full vehicle nonlinear Active Suspension System," International Journal on Smart Sensing and Intelligent Systems Vol. 4, No. 2, June 2011.

[4] Jie He, Hui Guo," A Modified Particle Swarm Optimization Algorithm," TELKOMNIKA, Vol. 11, No. 10, October 2013, pp. $6209 \sim 6215$

[5] Faraz Ahmed Ansari, RajShree Taparia, "Modeling, Analysis and Control of Active Suspension System using Sliding Mode Control and Disturbance Observer," International Journal of Scientific and Research Publications, Volume 3, Issue 1, January 2013.

[6] Bhuwaneshwar Chandekar1, Hemant D. Lagdive, "Design of Electro-Hydraulic Active Suspension System for Four Wheel Vehicles," International Journal of Emerging Technology and Advanced Engineering Website: www.ijetae.com (ISSN 2250-2459,ISO 9001:2008Certified Journal, Volume 4, Issue 4, April 2014).

[7] Shpetim Lajqi, Stanislav Pehan," Designs and Optimizations of Active and Semi-Active Non-linear Suspension Systems for a Terrain Vehicle," Journal of Mechanical Engineering 58(2012)12, 732-743.
[8] Sayel M. Fayyad, "Constructing Control System for Active Suspension System," Contemporary Engineering Sciences, Vol. 5, 2012, no. 4, 189 - 200.

[9] Senthilkumar Mouleeswaran (2012). Design and Development of PID Controller-Based Active Suspension System for Automobiles, PID Controller Design Approaches - Theory, Tuning and Application to Frontier Areas, Dr. Marialena Vagia (Ed.), ISBN: 978953-51-0405-6, InTech

[10] M. D. Donahue and J. K. Hedrick, "Implementation of an Active Suspension, Preview Controller for Improved Ride Comfort," ch no. 1, "Nonlinear and Hybrid System in Automotive Control" Johansson, R. and Rantzer, A. (Eds.) 2003, XVIII, 446 p., Hardcover ISBN: 978-185233-652-3.

[11] Goegoes Dwi Nusantoro and Gigih Priyandoko, "PID State Feedback Controller of a Quarter Car Active Suspension System", Journal of Basic and Applied Scientific Research 1 (11)

[12] Kurniawan Eka Permana and Siti Zaiton Mohd Hashim, ",Fuzzy Membership Function Generation using Particle Swarm Optimization", Int. J. Open Problems Compt. Math., Vol. 3, No. 1, March 2010.

[13] Binitha S and S Siva Sathya," A Survey of Bio inspired Optimization Algorithms", International Journal of Soft Computing and Engineering (IJSCE) ISSN: 2231-2307, Volume-2, Issue-2, May 2012. 